\title{
HUBUNGAN TINGKAT STRES PSIKOLOGIS DENGAN SIKLUS MENSTRUASI PADA MAHASISWA
}

\author{
1|Mei Lina Fitri Kumalasari, 2|Moch. Irfan Hadi, 3|Misbakhul Munir \\ Email Korespondensi : meilina fitri@uinsby.ac.id \\ Universitas Islam Negeri Sunan Ampel Surabaya, Indonesia
}

\begin{abstract}
The menstrual cycle is the distance between the first day of menstruation and the first period of the next menstruation. One of the faktors that influence the menstrual cycle is stres. Stres can stimulate the release of the hormone cortisol, which is a product of glucocorticoid adrenal cortex. This hormone affects the amount of progesterone in the body. This hormonal imbalance will cause changes in the menstrual cycle. The purpose of this study was to analyze the relationship between stres levels and the menstrual cycle of UIN Sunan Ampel Surabaya students. This research was an observational analytic study with a sampling design using simple random sampling with a total of 30 respondents. Data collection techniques use the DASS 42 questionnaire to measure stres levels and the menstrual cycle pattern questionnaire to measure the menstrual cycle. Data analysis using Fisher's exacs test and the results obtained $p=0.031$, so it means that there is a relationship between the level of stres with the menstrual cycl.
\end{abstract}

\begin{abstract}
Abstrak
Siklus menstruasi adalah jarak antara hari pertama menstruasi dengan hari pertama pada menstruasi berikutnya. Hal ini dapat dipengaruhi oleh stress yang merangsang pengeluaran hormone kortisol yang merupakan produk dari glukokortiroid korteks adrenal yang disintesis di zona fasikulata. Hormon ini mempengaruhi jumlah hormone progesterone di dalam tubuh. Ketidakseimbangan hormon ini akan menyebabkan perubahan siklus menstruasi. Tujuan dari penelitian ini adalah untuk mengetahui hubungan antara tingkat stres dengan siklus menstruasi mahasiswai UIN Sunan Ampel Surabaya. Penelitian ini merupakan penelitian observasional analitik dengan desain pengambilan sampel menggunakan simple random sampling dengan jumlah 30 responden. Tehnik pengumpulan data menggunakan kuesioner DASS 42 untuk mengukur tingkat stres dan kuesioner pola siklus menstruasi untuk mengukur siklus menstruasi. Analisis data menggunakan Fisher's exacs test dan didapatkan hasil nilai $p=0.031$. Hal ini berarti menunjukkan bahwa ada hubungan hubungan antara tingkat stres dengan siklus menstruasi. Penelitian selanjutnya sebaiknya menambahkan variabel lain yang mempengarusi siklus menstruasi dan menamba jumlah sampel agar diperoleh data yang lebih baik.
\end{abstract}

\section{Kata Kunci: Stres; Siklus Menstruasi; Remaja}

\section{PENDAHULUAN}

Remaja adalah masa peralihan dari anak-anak menjadi dewasa. WHO membagi remaja menjadi kelompok remaja awal pada usia 13-14 tahun, remaja tengah pada usia 15-17 tahun dan remaja akhir pada usia 18-21 tahun (1). Masa remaja ditandai dengan adanya pubertas dan pada wanita ditandai dengan datangnya menstruasi pertama kali yang disebut dengan menarche (2).

Mentruasi adalah perdarahan yang terjadi secara periodik dari uterus dan disertai dengan pelepasan endometrium. Setiap bulan wanita mengeluarkan sel telur yang matang dari salah satu indung telur sebelah kiri atau sebelah kanan secara bergantian. Dinding rahim akan menebal dan apabila tidak terjadi pembuahan maka akan rusak dan luruh keluar sebagai darah menstruasi (3). 
Jarak antara hari pertama menstruasi dengan menstruasi berikutnya disebut dengan siklus menstruasi. Normalnya wanita mengalami siklus menstruasi antara 21-35 hari. Siklus menstruasi rata-rata terjadi sekitar 28 hari (4).

Lama siklus menstruasi dapat menggambarkan keadaan organ reproduksi dan sistem hormonal seseorang. Selain itu, apabila siklus mestruasinya normal juga dapat memudahkan dalam menghitung masa subur. Seorang wanita rata-rata mengalami menstruasi teratur pada usia 18 tahun (5).

Sepanjang wanita mengalami menstruasi, pasti pernah mempunyai riwayat pola siklus menstruasi yang tidak teratur (6). Siklus menstruasi yang memanjang lebih dari 35 hari yang dinamakan oligomenore, siklus menstruasi yang kurang dari 21 hari dinamakan polimenorea serta yang tidak menstruasi selama tiga bulan berturut-turut dinamakan amenorea (7).

Pola siklus menstruasi dipengaruhi oleh faktor hormonal, kelainan sitemik, kelebihan hormone prolackin, IMT, usia menarche, aktivitas fisik dan stres (8). Stres ini merupakan suatu respon terhadap proses adaptasi dan penaturan tekanan internal dan tekanan luaran (stresor). Stres melibatkan sistem neuroendrokrinologi yang berperan dalam reproduksi wanita (9).

Wanita yang mengalami stres mengeluarkan hormone kortisol yang merupakan produk dari glukokortiroid korteks adrenal yang disintesis di zona fasikulata. Hormon ini mempengaruhi jumlah hormone progesterone di dalam tubuh. Ketidakseimbangan hormon ini akan menyebabkan perubahan siklus menstruasi (10).

Hasil penelitian dari Nasution pada tahun 2010 di Fakultas Kedokteran Universitas Sumatera Utara dengan 139 responden menunjukkan bahwa 110 mahasiswa $(79,1 \%)$ mengalami stres dan 26 mahasiswa $(23,7 \%)$ diantaranya mengalami siklus menstruasi yang tidak teratur (11). Penelitian dari Hazanah pada tahun 2013 pada 132 mahasiswa Program Studi D III Kebidanan Poltekkes Kemenkes Kalimantan Timur juga menunjukkan bahwa 50,8\% responden atau 67 mahasiswa mengalami stres dan 31 responden (45,5\%) diantaranya mengalami siklus menstruasi yang tidak teratur (Hazanah, 2013). Sedangkan penelitian dari Yudita pada tahun 2017 menyebutkan bahwa tidak ada hubungan antara tingkat stres dengan pola siklus menstruasi (12).

Berdasarkan beberapa penelitian di atas, maka poerlu dilakukan penelitian lebih lanjut tentang hubungan tingkat stres dengan pola siklus menstruasi. Penelitian ini dilakukan pada mahasiswi baru UIN Sunan Ampel Surabaya karena mahasiswa baru masih beradaptasi dengan sistem perkuliahan antara mempelajari materi kuliah dan materi wajib keagamaan pada semester awal. Hal ini dapat memicu stress pada mahasiswa . Tujuan dari penelitian ini adalah mengetahui hubungan antara tingkat stres dengan siklus menstruasi.

\section{METODOLOGI PENELITIAN}

Penelitian ini merupakan penelitian observasional analitik dengan desain studi cross sectional. Penelitian dilakukan pada bulan September 2019 di UIN Sunan 
Ampel Surabaya. Tehnik sampling yang digunakan adalah simple random sampling dengan jumlah 30 responden. Kriteria inklusi dalam penelitian ini adalah mahasiswa baru dan bersedia menjadi responden, sedangkan kriteria ekslklusinya adalah mahasiswa lama dan menolak untuk dijadikan responden.

Variabel penelitian terdiri dari variabel independen tingkat stres dan variabel dependent yaitu siklus menstruasi. Stres diukur dengan kuesioner Depression Anxiety Stres Scale 42 (DASS 42) (13). Penelitian ini membagi stres menjadi 5 tingkatan, yaitu:

1. Normal

2. Stres ringan

3. Stres sedang

4. Stres berat

5. Stres sangat berat : skor $>34$
: skor 0-14

: skor $15-18$

skor $19-25$

: skor 26-33

Sedangkan siklus menstruasi diukur dengan kuesioner pola siklus menstruasi dan dikelompokkan menjadi:

1. Siklus normal jika siklus menstruasi berkisar antara $21-35$ hari

2. Siklus tidak normal jika polimenorea, oligomenorea dan amenore sekunder. Analisis data yang digunakan pada penelitian ini adalah Fisher's exact test.

\section{HASIL PENELITIAN}

Tabel 1. Distribusi Frekuensi dan Persentase Tingkat Stres

\begin{tabular}{lll}
\hline Tingkat Stres & Frekuensi & Persentase (\%) \\
\hline Normal & 0 & 0 \\
Stres Ringan & 5 & 16.7 \\
Stres Sedang & 8 & 26.7 \\
Stres Berat & 5 & 16.7 \\
Stres Sangat Berat & 12 & 40 \\
\hline Jumlah & 30 & 100 \\
\hline
\end{tabular}

Berdasarkan tabel 1 diketahui bahwa mayoritas responden sebanyak 12 mahasiswi masuk dalam kategori kelompok stres sangat berat (40\%).

Tabel 2. Distribusi Frekuensi dan Persentase Siklus Menstruasi

\begin{tabular}{lll}
\hline Siklus Menstruasi & Frekuensi & Persentase (\%) \\
\hline Normal & 17 & 56,7 \\
Tidak normal & 13 & 43,3 \\
\hline Jumlah & 30 & 100 \\
\hline
\end{tabular}

Berdasarkan tabel 2 diketahui bahwa mayoritas responden sebanyak 17 mahasiswi masuk dalam kategori mempunyai siklus menstruasi yang normal $(56,7 \%)$. 
Tabel 3. Tabel Silang Tingkat Stres dan Siklus Menstruasi

\begin{tabular}{|c|c|c|c|}
\hline \multirow[t]{2}{*}{ Tingkat Stres } & \multicolumn{2}{|c|}{ Siklus Menstruasi } & \multirow[t]{2}{*}{ Total } \\
\hline & Normal & Tidak Normal & \\
\hline Normal & 0 & 0 & 0 \\
\hline Stres Ringan & 5 & 0 & 5 \\
\hline Stres Sedang & 6 & 2 & 8 \\
\hline Stres Berat & 1 & 4 & 5 \\
\hline Stres Sangat Berat & 5 & 7 & 12 \\
\hline Jumlah & & 13 & 30 \\
\hline
\end{tabular}

Berdasarkan table 3 diketahui bahwa mayoritas responden mempunyai tingkat stres sangat berat dan mempunyai siklus menstruasi yang tidak normal ( 7 responden).

Data dianalisis dengan Fisher's exact test dan didapatkan nilai p sebesar 0.031 $(\mathrm{p}<0,05)$. Dari hasil tersebut didapatkan hasil bahwa ada hubungan antara tingkat stress psikologis dengan siklus menstruasi pada mahasiswa UIN Sunan Ampel Surabaya.

\section{PEMBAHASAN}

Tingkat stres dapat dipengaruhi oleh respon seseorang terhadap stresor atau tekanan. Respon dapat diedakan menjadi respon kognitif, respon emosi, respon tingkah laku dan respon fisiologis. Selain itu, tingkat stres tiap orang dapat berbeda karena dipengaruhi oleh mekanisme koping (14). Selain itu tingkat stres juga dipengaruhi oleh faktor kemampuan menerka kejadian stres, kemampuan mengendalikan stres, evaluasi kognitif, kepercayaan diri atas kemampuan melawan tekanan dan dukungan orang-orang di sekitar (15).

Responden pada penelitian ini mempunyai siklus menstruasi yang normal sebanyak 17 orang $(56,7 \%)$ dan tidak normal sebanyak 13 orang $(43,3 \%)$. Hal ini sejalan dengan penelitian dari Yudita pada tahun 2017 yang menunjukkan bahwa mayoritas respondennya mempunyai siklus menstruasi yang normal (12). Penelitian dari Yamamoto pada tahun 2009 pada mahasiswi di Universitas Fakuoka Jepang juga menunjukkan bahwa dari 221 orang responden, terdapat 161 orang $(72,9 \%)$ mempunyai siklus menstruasi normal (16).

Siklus mesntruasi dipengaruhi oleh hormone reproduksi. Remaja biasa mengeluhkan perasaan kurang nyaman, mudah tersinggung, cepat marah dan nyeri pada oerut bawah pada waktu sedang menstruasi atau menjelang menstrusi. Hipotalamus akan mengeluarkan hormone gonadotropin yang dapat merangsang hipofisis untuk mengeluarkan hormone FSH pada akhir siklus menstruasi (3).

Berdasarkan hasil uji analisis data dengan Fisher's exact test, diperoleh nilai p sebesar 0.031 . Nilai $\mathrm{p}<0.05$ sehingga hal ini menunjukkan bahwa terdapat hubungan antara tingkat stres dengan siklus menstruasi.

Remaja yang mengalami stres akan mengeluarkan hormon kortisol yang merupakan produk dari glukokortiroid korteks adrenal dan disintesis di zona 
fasikulata. Hormon ini mempengaruhi jumlah hormon progesterone di dalam tubuh. Ketidakseimbangan hormon ini akan menyebabkan perubahan siklus menstruasi (10). Stimulus stres pada hipotalamus akan menghambat pelepasan hormone FSH dan LH ke organ-organ reproduksi. Hal ini akan mengganggu siklus menstruasi(17).

Hasil penelitian ini juga sesuai dengan penelitian yang dilakukan oleh Ekpenyong pada tahun 2011 pada mahasiswa Universitas Uyo di Nigeria bahwa ada hubungan antara stres akademik dengan gangguan siklus menstruasi. Sebanyak $19,9 \%$ responden mengalami oligomenorea dan sebanyak 5,9\% responden mengalami amenorea sekunder selama masa ujian. Penelitian ini juga mengungkapkan bahwa mahasiswi yang mempunyai tinkat stres yang tinggi, mempunyai peluang dua kali lipat untuk mengalami gangguan siklus menstruasi dibansingkan dengan yang mempunyai tingkat menstruasi yang rendah (18).

\section{KESIMPULAN}

Berdasarkan penelitian di atas maka didapatkan hasil dari tabel 3 bahwa ada hubungan antara tingkat stres dengan siklus menstruasi remaja. Mahasiswi UIN Sunan Ampel Surabaya mayoritas mempunyai tingkat stres sangat berat dan mempunyai siklus menstruasi yang tidak normal (7 responden).

\section{SARAN}

1. Untuk remaja putri sebaiknya dapat menghindasi stres dan mempunyai manajemen koping yang baik agar tidak mempengaruhi siklus menstruasi.

2. Untuk tenaga ksehatan sebaiknya meningkatkan pemberian informasi tentang mensntruasi dan tata kelola stres agar remaja menjadi lebih tahu tentang kesehatan reprouksinya.

3. Untuk peneliti selanjutnya dapat mengidentifikasi faktor yang lainnya agar diperoleh hasil penelitian yang lebih kompleks dan akurat.

\section{DAFTAR PUSTAKA}

1. Dariyo A. Psikologi Perkembangan Remaja. Bogor: Ghalia Indonesia; 2004.

2. Wong LD. Buku Ajar Keperawatan Pediatrik (Wong's Essential of Pediatric Nursing). Jakarta: EGC; 2013.

3. Wijayanti D. Fakta Penting Seputar Kesehatan Reproduksi Wanita. Jogjakarta: Book Marks; 2015.

4. Wiknjosastro H. Ilmu Kandungan. Jakarta: Yayasan Bina Pustaka Sarwono Prawirohardjo; 2011.

5. Manuaba I. Memahami Kesehatan Reproduksi Wanita. Jakarta: EGC; 2009.

6. Kumalasari MLF. Correlation Between Body Mass Index with Menstrual Cycle on Female Adolescent. International Conference on Sustainable Health Promotion. 2018 Oct 9;100-3.

7. Greydanus DE, McAnarney ER. Menstruation and its disorders in adolescence. Curr Probl Pediatr. 1982 Aug;12(10):1-61. 
8. Andriana, Aldriana N, Andria. Faktor-Faktor Yang Mempengaruhi Siklus Menstruasi pada mahasiswi di Universitas Pasir Pengaraian. Jurnal Maternity and Neonatal. 2018;2(5).

9. Christian M. Jinakkan Stres: Kiat Hidup Bebas Tekanan. Bandung: Nexx; 2015.

10. Chomaria N. Tips Jitu dan Praktis Mengusir Stres. Yogyakarta: Diva Press; 2013.

11. Nst IS. Hubungan Stres Dengan Siklus Menstruasi Yang Tidak Teratur Pada Mahasiswi Fakultas Kedokteran Usu Angkatan 2007. [Medan]: Universitas Sumatera Utara; 2010.

12. Yudita NA, Yanis A, Iryani D. Hubungan antara Stres dengan Pola Siklus Menstruasi Mahasiswi Fakultas Kedokteran Universitas Andalas. JKA. 2017 Oct 12;6(2):299.

13. Lovibond S.H. Manual for the Depression, Anxiety and Stress Scales (Second Edition). Psychology Foundatiom; 1995.

14. Nasir A, Abdul M. Dasar-dasar Keperawatan Jiwa: Pengantar dan Teori. Jakarta: Salemba Medika; 2011.

15. Sood M, Devi A, Mohd Daher AA, Razali S, Nawawi H, Hashim S, et al. Poor Correlation of Stress Levels and Menstrual Patterns among Medical Students. jABs. 2017 Nov 4;2(5):73.

16. Yamamoto K, Okazaki A, Sakamoto Y, Funatsu M. The Relationship between Premenstrual Symptoms, Menstrual Pain, Irregular Menstrual Cycles, and Psychosocial Stress among Japanese College Students. Journal of PHYSIOLOGICAL ANTHROPOLOGY. 2009;28(3):129-36.

17. Muniroh S, Widiatie W. (The Relationship Of Stress Level With Adolescent Menstruation Cycle Disorder). 2017;10.

18. Ekpenyong CE, Davis KJ, Akpan UP, Daniel NE. Academic stress and menstrual disorders among female undergraduates in Uyo, South Eastern Nigeria - the need for health education. Niger J Physiol Sci. 2011 Dec 20;26(2):193-8. 